\title{
TIEMPO, ETERNIDAD Y DISTENTIO ANIMI. UNA CLAVE DE LECTURA DEL LIBRO XI DE CONFESIONES
}

\author{
Jonathan Triviño CuellaR* \\ doi:10.11144/Javeriana.uph33-67.teda
}

\begin{abstract}
RESUMEN
En la reflexión agustiniana, el análisis del tiempo deriva de su condición misma de creatura; por esta razón, el tiempo resulta ser como es, es decir, resulta tener esa precariedad ontológica que comparte con todo lo creado. Cuando preguntamos por el tiempo, descubrimos que esta realidad no es algo más que nuestro entendimiento pueda abordar a la manera como se toma un objeto desconocido, sino que esta noción se nos revela como una dimensión de nuestro ser. En presente artículo propongo una clave de interpretación del libro XI de Confesiones en el cual muestro la importancia de presentar el sentido de la existencia temporal de cara al Creador eterno, así como propongo una interpretación de la dimensión doble, positiva y negativa, de la distentio animi.
\end{abstract}

Palabras clave: Agustín; Confesiones; distentio animi; tiempo; eternidad

* Pontificia Universidad Javeriana, Bogotá, Colombia.

Correo electrónico: jtrivino@javeriana.edu.co; juanathan2005ster@gmail.com

Para citar este artículo: Triviño Cuellar, J. (2016). Tiempo, eternidad y distentio animi. Una clave de lectura del libro XI de Confesiones. Universitas Philosophica, 33(67), pp. 239-274.

ISSN 0120-5323, ISSN en línea: 2346-2426, doi:10.11144/Javeriana.uph33-67.teda 


\title{
TIME, ETERNITY AND DISTENTIO ANIMI. A READING KEY OF CONFESSIONS, BOOK XI
}

\author{
Jonathan Triviño CUellar
}

\begin{abstract}
In the Augustinian reflection on time, the analysis derives from its condition as a creature; for this reason, the time turns out to be as it is, that is, turns out to have this ontological precariousness that shares with all creation. When we asked about the time, we discover that this reality is not something that our understanding can address as when a man takes an unknown object, but this notion is revealed to us as a dimension of our being. In this article, I propose an interpretation key of the Book XI of Confessions in which I show the importance of presenting the sense of temporal existence facing the eternal Creator and also I propose an interpretation of the dual dimension, positive and negative, of distentio animi. Key words: Augustine; Confessions; distentio animi; time; eternity
\end{abstract}




\section{Introducción}

EN LA REFLEXIÓN AgUSTINIANA, EL ANÁlisis DEL TIEMpo deriva de su condición misma de creatura; por esta razón, el tiempo resulta ser como es, es decir, tiene esa precariedad ontológica que comparte con todo lo creado. Aunque el tiempo es creado, su complejidad es notoriamente mayor a nivel ontológico que la que se puede encontrar en las demás realidades creadas, aparte del ser humano mismo, ya que la pregunta por el tiempo surge en el contexto de la pregunta por la creatura creada a imagen y semejanza, es decir, el hombre ${ }^{1}$. Las cosas que hay en el tiempo no son precarias por estar en el tiempo, sino porque son creadas. El tiempo también es una creación de Dios, pero no se puede comprender al modo como aprehendemos las demás cosas creadas. De tal manera que, la fenomenología del tiempo en San Agustín, debe comprenderse desde la ontología y no al revés, como parece haber sido asumido por las interpretaciones tradicionales. Para entender el tiempo como el santo lo comprende, debemos primero ampliar la cuestión al sentido mismo de la existencia temporal; así, el problema del tiempo va ligado al asunto de su sentido. Uno de los problemas que podemos descubrir junto a Agustín es que aprehender la realidad del tiempo es algo contradictorio, porque queremos aprehender la realidad que es el propio devenir y que, por tanto, no podemos aprehenderlo de ningún modo. Primero tenemos que ver cómo debemos aprehenderlo y, a partir de esto, ver todo lo creado en el tiempo, lo que nos conduce a vislumbrar su contraste con la eternidad. De este modo, descubrimos que tiempo y eternidad son inconmensurables (incomparabiles). Cuando pensamos el tiempo reconocemos, a la vez, su carácter transitorio, es decir, su no permanencia; constatamos el pasar del tiempo y, asimismo, reconocemos el ser inmutable de la eternidad, su permanencia; sin embargo, existe una relación

1 La mutabilidad propia del tiempo nos conduce a comprender mejor la eternidad divina y en medio de estas dos dimensiones inconmensurables se encuentra la existencia humana. Esta dialéctica tiempo-eternidad se ve reconciliada en el hombre, ya que, por ser imagen y semejanza del Creador (Cricco, 2006, p. 1), está llamado a participar de la naturaleza eterna de Dios y, por ser creatura, es temporal. "A través de las cuestión del tiempo, se contempla necesariamente la naturaleza del hombre y su relación con Dios" (Avramenko, 2007, p. 782). En este sentido, el hilo de la argumentación agustiniana es la comparación entre Dios y la criatura (Alaux, 1999, p. 1). Luego, debemos centrar nuestra atención en Dios, que tomó la condición humana en Jesucristo, el Verbo encarnado, el único mediador entre Dios y los hombres, y se hizo temporal para que el hombre llegara a ser eterno. 
esencial entre la tiempo y la eternidad, en esto radica el enigma mismo del tiempo. "En la eternidad de Dios no hay cambio, no hay antes ni después" (Gunnersdorf von Jess, 1975, p. 80).

Antes de abordar los problemas internos del tratado sobre el tiempo, se hace necesario mostrar cuál es la estructura del libro para poder tener una comprensión mejor de las cuestiones que trata el santo en esta parte de Confesiones ${ }^{2}$. El libro puede dividirse en cuatro partes: en la primera, que también hace las veces de introducción, el santo declara el énfasis y giro hermenéutico que tiene el libro y abre la discusión sobre el tiempo (XI, 1, 1 - XI, 13, 16); en la segunda, plantea las paradojas del tiempo y establece la prioridad ontológica del tiempo presente (XI, 14, 17 - XI, 21, 27); en la tercera, establece las relaciones entre la medida del tiempo, el espacio y el movimiento (XI, 23, 29 - XI, 24, 31); en la cuarta, afirma que el tiempo es distentio animi (XI, 26, 33- XI, 28, 38). Además, tenemos dos tránsitos y una conclusión: el primer tránsito en XI, 22, 28, donde el santo eleva una súplica a Dios pidiendo su auxilio para entender mejor el enigma del tiempo; el segundo, en XI, 25, 32, donde declara su ignorancia frente al asunto; y, finalmente, la conclusión de XI, 29, 39 a XI, 31, 41.

2. Creación, tiempo y eternidad (XI, 1, 1 - XI, 13, 16)

DESDE LA PRIMERA LÍNEA DEL LIBRo XI, identificamos el asunto en el que se va a ocupar Agustín, esto es, el tiempo en relación con la eternidad. Además, podemos notar que el libro XI parece indicar un nuevo comienzo, donde tiene lugar un nuevo alcance cósmico y hermenéutico en el modo como el santo aborda el tema de la creación (Hochschild, 2012, p. 155); sin embargo, aunque los especialistas usualmente están de acuerdo en que dicho comienzo se da a partir de la cita de los versos de la Escritura en XI, 3, 5: "Oiga yo y entienda cómo biciste en

2 En este punto es importante resaltar que uno de los elementos esenciales que atraviesa la estructura de Confesiones y, por ende, el libro XI, es su carácter dinámico, ascendente y universalizador. "Se trata, en efecto, de presentar el estado de caída, el movimiento de conversión, y el anticipo de plenitud, encuadrado todo ello en Dios como origen y en Dios como meta del ser humano, tanto individual, como colectivo" (Flórez, 2008, p. 84). La investigación agustiniana a lo largo de Confesiones va subiendo de nivel ontológico hacia lo que no cambia, de tal suerte que ya de entrada en el libro XI, el santo plantea la pregunta por el tiempo y su relación con la eternidad, porque en el hombre hay una sed de lo permanente, que solo en Dios, el eterno, puede saciarse. 
el principio el cielo y la tierra", creemos conveniente, para el propósito de nuestra investigación, resaltar el modo como Agustín empieza el libro XI y su vínculo con los textos iniciales de Confesiones.

Ya desde el comienzo del libro, el santo nos anuncia el tema: “¿Por ventura, Señor, siendo tuya la eternidad, ignoras las cosas que te digo, o ves en el tiempo lo que se ejecuta en el tiempo?" e inmediatamente, repite la invocación de los Salmos 144:3 y 95:4, con la cual Agustín había empezado su obra: "Pues ¿̨por qué te hago relación de tantas cosas? No ciertamente para que las sepas por mí, sino que excito con ellas hacia ti mi afecto y el de aquellos que leyeren estas cosas, para que todos digamos: Grande es el Señor y laudable sobremanera. Ya lo he dicho y lo diré: por amor de tu amor hago esto" (Conf. XI, 1, 1) $)^{3}$. De esta manera, se hace evidente que hay un renovado énfasis en el propósito de la confesión, de tal suerte que no es casual la repetición de las primeras frases de la obra, sino que el santo nos previene del cambio y acento que ahora tiene la obra en esta parte final.

En los cuatro primeros parágrafos podemos reconocer esta reorientación y acento de Confesiones, ya que no solo repite la invocación de los salmos arriba mencionados, sino que las referencias bíblicas y el contexto son semejantes, además del uso del verbo excitare, que nos permiten ver la agudeza del santo en su modo de abrir su obra y de cerrarla en estos últimos tres libros como un nuevo comienzo. Tanto al principio del libro primero como en la apertura del libro undécimo, el contexto es semejante, ya que en ambos Agustín pide el auxilio de Dios Padre que hizo el cielo y la tierra, de tal suerte que en ambos libros el contexto es creacional. Sin embargo, en el libro primero la alabanza se orienta a exaltar la grandeza divina como apertura de su confesión, mientras que en el libro undécimo la alabanza gira en torno a pedir el auxilio divino para poder referir y escribir de forma adecuada su comprensión de la sentencia de Génesis 1:1: en el principio hizo Dios el cielo y la tierra, tal como aparece en el parágrafo 5: "Oiga yo y entienda cómo hiciste en el principio el cielo y la tierra. Moisés escribió esto, lo escribió y se ausentó; salió de aquí por ti, para ti, y ahora no le tengo delante de

3 En adelante, por mor de la brevedad, a lo largo del artículo para referirnos a Confesiones solo citaremos el libro, el capítulo y el parágrafo. Las versiones de las obras de San Agustín de las que hago uso son las traducciones al español de la BAC. Además es importante aclarar que la traducción de los textos que no tienen versión publicada en español tanto en inglés como en francés es mía. 
mí. Porque si estuviese le asiría, y rogaría, y conjuraría por ti, para que me declarase estas cosas, y yo prestaría los oídos de mi corazón a las palabras que brotasen de su boca”. En el libro primero era Dios quien excitaba el alma del hombre para que lo alabara y buscara: "Tú mismo le excitas a ello, haciendo que se deleite en alabarte, porque nos has hecho para ti y nuestro corazón está inquieto hasta que descanse en ti" (I, 1, 1); en el libro undécimo es el hombre Agustín quien excita su alma para que reconozca y busque la grandeza de su Creador: "Pues epor qué te hago relación de tantas cosas? No ciertamente para que las sepas por mí, sino que excito con ellas hacia ti mi afecto y el de aquellos que leyeren estas cosas, para que todos digamos: Grande es el Señor y laudable sobremanera (Salmos 95:4). Ya lo he dicho y lo diré: por amor de tu amor hago esto" (XI, 1, 1). La comprensión de la sentencia del Génesis exige que el santo ponga el acento de su confesión en la dimensión temporal del hombre iluminada por la eternidad divina. Es el hombre el que pide el auxilio divino para elevarse en la comprensión de su existencia temporal de cara a la eternidad de su Creador, aunque este propósito no surge solo por un acto de la voluntad humana, sino porque el mismo Dios ha querido que este anhelo nazca en su alma: "He aquí que te he referido muchas cosas: las que he podido y he querido, por haberlo querido tú primero" (XI, 1, 1).

En el parágrafo 3 el santo cita el libro del Génesis que reiterará en numeral 5, en ambos casos le da un particular acento a la palabra principio, que vinculará con el comienzo del Evangelio de Juan. La cita está en un contexto doble, de súplica y de alabanza, donde el santo pide el auxilio y luz de Dios para que, como ya se ha mencionado arriba, confiese todo cuanto Dios mismo le inspire de acuerdo con la Palabra revelada y no según sus deseos:

Dame espacio para meditar en los entresijos de tu ley y no quieras cerrarla contra los que pulsan, pues no en vano quisiste que se escribiesen los oscuros secretos de tantas páginas. ¿O es que estos bosques no tienen sus ciervos, que en ellos se alberguen, y recojan, y paseen, y pasten, y descansen, y rumien? ¡Oh, Señor!, perfeccióname y revélamelos [...] Te confesaré cuanto descubriere en tus libros y oiré la voz de la alabanza, y beberé de ti, y consideraré las maravillas de tu ley desde el principio, en el que hiciste el cielo y la tierra, hasta el reino de la tu santa ciudad, contigo perdurable. (XI, 2, 3)

Enseguida, en el parágrafo 4 podemos notar el vínculo inmediato con el pasaje de Juan 1:1-2: En el principio existía la Palabra, y la Palabra estaba con Dios, y 
la Palabra era Dios. Todo se hizo mediante ella, y sin ella nada se hizo, que le permitirá más adelante hacer el análisis del texto divino y la relación entre nuestra naturaleza temporal y la acción salvadora del Verbo eterno: "Te lo suplico por nuestro Señor Jesucristo, tu Hijo, el Varón de tu diestra, el Hijo del Hombre, a quien escogiste para ti, Mediador tuyo y nuestro, por quien nos buscaste cuando no te buscábamos y nos buscaste para que te buscásemos; Verbo tuyo, por quien hiciste todas las cosas, entre las cuales también a mí; Único tuyo, por quien llamaste a adopción al pueblo de los creyentes y en él a mí". La referencia a ambos pasajes bíblicos nos permite ver el asunto que ocupa al santo, que no es otro que pensar la creación en la cual también es creado el tiempo. En In Ioannis Evangelium Tractatus I del año 406, Agustín analiza juiciosamente estos versos de Juan y manifiesta la dificultad interna que el intérprete encuentra al tratar de comprender el texto sagrado. Por un lado, develar el misterio divino desborda la capacidad humana de comprensión, lo que nos indica la imposibilidad de asir la relación tiempo-eternidad y alma-Dios; por otro lado, el lenguaje humano es limitado y no puede expresar con claridad los misterios divinos, ni siquiera el autor del Evangelio pudo comprender en realidad lo que por inspiración divina se le había revelado:

Quizá así quedemos todos satisfechos, entendiendo cada uno hasta donde lleguen sus posibilidades, y el orador exponiendo hasta donde él puede. Porque ¿quién podrá hablar de estos misterios como ellos son? Me atrevo a decir más, hermanos míos: quizá ni el mismo Juan habló de estas realidades como son en sí, sino como le fue posible. Él es un hombre que habla de Dios. Por estar inspirado pudo decir algo. Sin la inspiración no habría podido decir nada. Pero al ser un hombre inspirado, expresó no toda la realidad, sino aquella que es capaz de decir el hombre. (Jo.ev.tr. I, 1)

De esta manera, podemos notar cómo los parágrafos 3 y 4 no solo cumplen la tarea de ser un preámbulo para el parágrafo que los comentaristas han privilegiado por su referencia explícita al acto creacional de XI, 3, 5: "Oiga yo y entienda cómo hiciste en el principio el cielo y la tierra”, sino que la interpolación de Génesis con los primeros versos de Juan nos da la clave para comprender el lugar capital de la acción del Verbo en la Creación y cómo en Él el vínculo entre tiempo y eternidad se hace más evidente. En este punto se muestra por qué "Agustín sigue estando principalmente preocupado con la cuestión de cómo lo temporal puede venir unido a lo eterno" (Hochschild, 2012, p. 156); es decir, el santo se pregunta 
por el carácter mediador de Cristo, y cómo, por su acción, se manifiesta una unidad entre tiempo y eternidad, así como muestra de qué forma es posible superar la condición temporal y las dificultades de la vida corpórea en la paz que se encuentra en la eternidad. "Su fenomenología de la temporalidad busca reconocer, y confesar, el contraste entre la intrínseca transitividad de la creatura y la permanencia del Creador increado y, correlativamente, para revelar la urgencia de la relación estabilizante con él proporcionada por el Mediador” (Pic, 2009, p. 252).

Al principio del numeral 6 Agustín comenta el texto diciendo: "He aquí que existen el cielo y la tierra, y claman que han sido hechos, porque se mudan y cambian. Todo, en efecto, lo que no es hecho y, sin embargo, existe, no puede contener nada que no fuese ya antes, en lo cual consiste el mudarse y variar". Nótese cómo ya, de forma implícita, se hace referencia al tiempo, puesto que algo muda o cambia solo en virtud de su naturaleza temporal, de lo contrario se estaría hablando de la permanencia propia de la naturaleza divina y eterna. Así, podemos reparar en los contrarios que en el Verbo van a encontrar unidad, como tiempoeternidad y cambio-permanencia; por ello, Agustín en el numeral 7 se pregunta: "Pero ¿cómo hiciste el cielo y la tierra y cuál fue la máquina de tan gran obra tuya?", esto es, se hace la pregunta por la acción misma del Verbo en el acto creador, "porque Dios no se limita a llevar a la criatura a la existencia ex nibilo, sino que lo hace a través de la Palabra, in principium" (Hochschild, 2012, p. 156). Es en el Verbo divino donde todas las creaturas, incluyendo el tiempo, cobran existencia y, por eso, se dice en el principio, ya que con la primera creatura surge a la vez el tiempo. En consecuencia, el Hiponense no presupone el tiempo, sino que lo piensa desde el mismo momento de su creación para, de este modo, plantearse más adelante de manera explícita la pregunta por el ser del tiempo. Al interrogante por el cómo, Agustín responde diciendo que crear es el hablar de la divinidad: "Tú dijiste, y las cosas fueron hechas y con tu palabra las hiciste" (XI, 5, 7), esto es, la acción creadora se hace en el Verbo, pero no al modo como se dice una palabra que comienza y termina, sino que las palabras divinas son eternas, no pasan. Por eso, antes de que surgiera la primera creatura no existía el tiempo, de tal suerte que la Palabra divina creacional no está en el tiempo sino que es siempre presente, es eterna: "Mas antes del cielo y de la tierra no había ningún cuerpo, y si lo había, ciertamente lo habías hecho tú sin una voz transitoria de donde formases la voz transitoria, con la que dijeses que fuesen hechos el cielo y la tierra. 
Porque, sea lo que fuere, aquello de donde había de formarse tal voz, si no hubiese sido hecho por ti, no sería absolutamente nada" (XI, 6, 8). E inmediatamente enfatiza en el parágrafo 9:

Así, pues, tú nos invitas a comprender aquella palabra, que es Dios ante ti, Dios, que sempiternamente se dice y en la que se dicen sempiternamente todas las cosas. Porque no se termina lo que se estaba diciendo y se dice otra cosa, para que puedan ser dichas todas las cosas, sino todas a un tiempo y eternamente. De otro modo, habría ya tiempo y cambio, y no habría eternidad verdadera ni verdadera inmortalidad.

De este modo, se hace evidente la dependencia del tiempo con respecto a la eternidad. La negación explícita de la existencia del tiempo antes de que surgiera la creatura es de vital importancia para entender el carácter de creatura del tiempo y, de esta manera, comprender por qué el santo entiende el tiempo como imagen de la eternidad. Para Agustín es de suma importancia resaltar el carácter de criatura del tiempo, puesto que sin esta claridad el tiempo puede tenerse como algo ya dado donde se encuentran todas las realidades, incluyendo las divinas, lo que sería a todas luces una incomprensión de la naturaleza misma del tiempo y de su carácter de imitación de la eternidad. Puestas las realidades divinas en el tiempo, desaparece la eternidad y con ello todo lo divino en cuanto tal, pues uno de los atributos fundamentales de Dios es su eternidad. De esta forma, reconocemos que solo comprendemos algo de la esencia del tiempo si lo vemos de cara a la eternidad, ya que el tiempo mismo es una creación de Dios Eterno. Además, ya en este parágrafo el santo nos avisa de lo imperativo que es meditar sobre la segunda persona de la Trinidad, el Verbo, que nos alcanza desde su eternidad una comprensión mayor del tiempo, siendo Él el único que puede elevarnos de nuestra naturaleza temporal a la divina eternidad del Padre. En consecuencia, para comprender las palabras de los primeros versos del Génesis se hace necesaria una adecuada comprensión de la naturaleza doble del Verbo, puesto que en tanto hombre habla y su palabra tiene principio y fin, es decir, es temporal, pero en tanto Dios, su palabra permanece, es eterna: "Es el mismo Verbo tuyo, que es también Principio, porque nos habla. Así habla por la carne en el Evangelio, y así habló exteriormente a los oídos de los hombres, para que fuese creído, y se le buscase dentro, y se le hallase en la Verdad eterna, en donde el Maestro bueno y único enseña a todos los discípulos" (XI, 8, 10). 
Afirmar la naturaleza de creatura del tiempo significa afirmar su no existencia antes de que se hicieran el cielo y la tierra, de tal suerte que preguntar por el antes del tiempo es un absurdo y una pregunta ociosa que reside en una incomprensión de lo que es la eternidad. Esta incomprensión radica en una incomprensión aún mayor de la relación de la palabra creadora con lo creado, ya que "la palabra creadora, que es eterna, sin embargo, da cuenta del mundo transitorio que nos rodea. El único vínculo es que hay un vínculo. La desemejanza de la palabra a cualquier palabra nos hace pensar en la desemejanza de la luz a cualquier luz" (Conybeare, 2012, p. 107), es decir, pretender develar el misterio que está a la base de la relación tiempo y eternidad es pretender comprender lo incomprensible y ahí radican todas las interpretaciones equivocadas del texto sagrado y, también, del pensamiento agustiniano.

A este respecto es importante decir que ya, desde la pregunta que encabeza el libro XI, la naturaleza divina se manifiesta como una realidad que está fuera del tiempo y su acción no está ligada al tiempo; sin embargo, podemos preguntar: ¿cuál es, pues, el vínculo de Dios con la realidad temporal? ¿Cuál es el sentido de interrogar al Creador por el tiempo? Literalmente, Dios está fuera del tiempo, pues Él mismo creó el tiempo cuando hizo el cielo y la tierra, tal como aparece en los primeros versículos del Génesis. De acuerdo con el Hiponense, solo hay tiempo si hay cambio y este solo se produce en la creatura, no en el Creador, de tal suerte que todo cuanto ha sido creado está sometido al tiempo. Agustín explica el tiempo como obra de Dios, pues su comienzo se da con la creación del mundo, debido a que en "Dios no hay tiempo, puesto que es inmutable, pero las cosas creadas cambian, y este cambio o movimiento es lo que entraña el tiempo" (Lacalle, 2006, p. 90). Tanto en Confesiones como en De civitate Dei, Agustín insiste que el tiempo depende del movimiento y, como Dios es inmóvil, entonces no hay tiempo antes de la creación (Conf. II, 13, 15; De civ. II, 6). "La creación es una actualización de la eterna e inmutable decisión de Dios: la voluntad de un cambio no implica un cambio de voluntad" (Knuuttila, 2002, p. 106). El Padre, al crear el cielo y la tierra, también crea el tiempo, no hay tiempo antes de la creación, de ahí que sea un sinsentido la pregunta por la acción divina antes de la Creación, puesto que en Dios no hay ni antes ni después: “¿Qué hacía Dios antes que hiciese el cielo y la tierra?” (XI, 10, 12). Hablar de antes y después es ya hablar en términos del tiempo, de tal suerte que el lenguaje humano encuentra un 
límite cuando trata de decir lo indecible de lo divino y eterno. Por esta razón, al hablar del misterio de la Creación se debe "considerar adecuadamente tanto las limitaciones de lo temporal, en perspectiva de la creatura, como las limitaciones del lenguaje humano" (Hochschild, 2012, p. 161). No podemos decir nada de lo eterno, sino solo aquello que nos ha sido revelado:

Quienes así hablan, todavía no te entienden, ¡oh sabiduría de Dios, luz de las mentes!; todavía no entienden cómo se hagan las cosas que son hechas en ti y por ti, y se empeñan por saber las cosas eternas; pero su corazón revolotea aún sobre los movimientos pretéritos y futuros de las cosas y es aún vano. ¿Quién podrá detenerle y fijarle, para que se detenga un poco y capte por un momento el resplandor de la eternidad, que siempre permanece, y la compare con los tiempos, que nunca permanecen, y vea que es incomparable, y que el tiempo largo no se hace largo sino por muchos movimientos que pasan y que no pueden coexistir a la vez, y que en la eternidad, al contrario, no pasa nada, sino que todo es presente, al revés del tiempo, que no puede existir todo él presente; y vea, finalmente, que todo pretérito es empujado por el futuro, y que todo futuro está precedido de un pretérito, y todo lo pretérito y futuro es creado y transcurre por lo que es siempre presente? (XI, 11, 13)

Con frecuencia, Agustín muestra tanto las intenciones torcidas de quienes creen preguntar algo importante cuando interrogan por el antes de la creación, como la incomprensión de estos del tiempo como creatura, ya que pretenden asimilar tiempo y eternidad o comprender lo eterno a partir de conceptos ligados al tiempo: "Mas si antes del cielo y de la tierra no existía ningún tiempo, ępor qué se pregunta qué era lo que entonces hacías? Porque realmente no había tiempo donde no había entonces [...] Tú hiciste todos los tiempos, y tú eres antes de todos ellos; ni hubo un tiempo en que no había tiempo" (XI, 13, 15-16). Nótese que en estos últimos numerales el santo ya nos avisa del problema central que abordará a partir del parágrafo 17 sobre la naturaleza misma del tiempo, su medida y la dificultad que trae comprender el tiempo pasado, el tiempo presente y el tiempo futuro.

3. Paradojas del tiempo (XI, 14, 17 - XI, 21, 27)

UNA VEZ HEMOS GANADO TERRENO en mostrar de qué forma surge el problema del tiempo en Confesiones, no como una cosa fenomenológicamente ya dada, 
sino como creatura, el santo se plantea de manera explícita la célebre pregunta por la realidad y naturaleza del tiempo: "¿Qué es, pues, el tiempo? (Quid est enim tempus?)” (XI, 14, 17). Este parágrafo ha sido sobreinterpretado a lo largo de los siglos, pero no debe comprenderse como desligado de lo que el santo ha dicho en los numerales 1 a 16, ya que de lo contrario se pierde el horizonte de sentido en el cual surge la pregunta por el tiempo y se termina en interpretaciones desproporcionadas. La pregunta por el tiempo se plantea, no por el tiempo mismo, sino con el fin de comprender mejor los versos iniciales de Génesis: en el principio hizo Dios el cielo y la tierra. El tiempo es una creatura y como tal debe ser comprendido; sin embargo, cuando nos planteamos la pregunta por el tiempo, descubrimos cuán poco podemos decir con claridad sobre esta realidad, ya que efectivamente pasa el tiempo, hay cambios, las creaturas tienen principio y fin y solo de Dios podemos decir con verdad que permanece. El tiempo es una realidad tan obvia que pasa desapercibida para la mayoría de los hombres, pues hace parte de nuestro modo habitual de hablar; de hecho, el lenguaje humano está atravesado por términos que remiten al tiempo y, por ello, pocos se preguntan por el hecho de que haya tiempo, esto es, pocas veces nos preguntamos por su ser. Por esta razón, el santo formula la primera de las paradojas que surgen a partir de la investigación sobre el tiempo:

¿Quién podrá explicar esto fácil y brevemente? ¿Quién podrá comprenderlo con el pensamiento, para hablar luego de él? Y, sin embargo, equé cosa más familiar y conocida mentamos en nuestras conversaciones que el tiempo? Y cuando hablamos de él, sabemos sin duda qué es, como sabemos o entendemos lo que es cuando lo oímos pronunciar a otro. ¿Qué es, pues, el tiempo? Si nadie me lo pregunta, lo sé; pero si quiero explicárselo al que me lo pregunta, no lo sé. (XI, 14, 17).

El asunto se nos muestra como algo evidente y, a la vez, oscuro y profundo. Agustín trata de comprender y mostrar qué es lo que habitualmente presuponemos cuando hablamos del tiempo en la conversación ordinaria (Vaught, 2005, p. 123). Hay una cierta comprensión del tiempo en nuestro modo habitual de hablar y, por esta razón, nos podemos entender unos con otros, pero cuando planteamos de manera explícita la pregunta por el tiempo, este parece escaparse de nuestras manos y quedamos perplejos cuando constatamos que no sabemos nada concreto sobre el tiempo, sino tan solo referencias a él, términos que dependen de él, pero 
no podemos asirlo. En el lenguaje ordinario no tenemos dificultad con el tiempo, ya que para todos es algo evidente, algo que se presupone y de lo que sería ocioso formularse una pregunta. Pero, en realidad, no sabemos qué es el tiempo y, no obstante, tenemos una cierta comprensión de él. La dificultad se torna, pues, en establecer qué es lo que propiamente podemos denominar tiempo y cuál es su situación ontológica. Cuando Agustín formula la pregunta por el tiempo hace evidente que no hay un concepto estable de tiempo y, por tanto, se hace imperativo pensar qué es lo que nombramos como tiempo para procurar establecer a qué nos referimos cuando hablamos de él. Parece que Agustín encuentra que el concepto mismo del tiempo comparte la misma naturaleza de lo que nombra, es decir, su inestabilidad, ya que el tiempo es el devenir mismo, su ser radica en que pasa.

Cuando el santo formula la pregunta ¿qué es pues el tiempo?, podemos decir que el énfasis de la pregunta está puesto en el verbo, es decir, pregunta por el ser del tiempo. Agustín quiere ir más allá del flujo propio del tiempo y de su concepto, ya que ambos van ligados a la naturaleza misma de la existencia temporal del que pregunta; de ahí que para comprender el tiempo se haga necesario remontarse a la eternidad. El santo se plantea la pregunta por el tiempo con el fin de comprender y meditar mejor la Ley de Dios que es eterna. Esta búsqueda de estabilidad para poder meditar la ley divina, a partir de la cuestión "¿Qué es pues el tiempo? (Quid est enim tempus?)”, corresponde a la búsqueda de estabilidad que surge de la pregunta previa del comienzo del libro noveno ":Quién soy y qué soy yo? (Quis ego et qualis ego?)”’. En ambos contextos, “Agustín está buscando la estabilidad, donde la relación entre Dios y el alma puede proporcionar un marco estable en el que se desenvuelve su existencia temporal" (Vaught, 2005, p. 124), es decir, la pregunta por el tiempo y la pregunta por su existencia se comprenden dentro de un contexto de inestabilidad propio de la existencia humana temporal de cara a la eternidad que es permanente y estable. En los primeros diez libros de Confesiones, Agustín se plantea la pregunta por su propio ser, ¿quién soy? Ahora, en el libro XI, pregunta por el tiempo, ¿qué es el tiempo?, pero teniendo en cuenta que el que interroga, pregunta en el tiempo y su existencia es temporal, lo que nos pone en la misma situación de desgarro del alma del libro décimo: "Y tú,

4 Aunque la traducción de la BAC es a la letra ¿Quién fui yo y qué tal fui?, el texto latino también puede traducirse como ¿quién soy yo y qué soy yo? 
Señor Dios mío, escucha, mira y ve, y compadécete y sáname; tú, en cuyos ojos estoy hecho un enigma, y ésa es mi enfermedad"s $(X, 33,50)$, ya que se anhela entender algo que en sí mismo es un misterio profundo y que solo en Dios podremos entender. Así, notamos que al preguntar por el tiempo se pregunta a la vez por la propia existencia.

Al comienzo de este artículo hemos defendido que en el libro XI tiene lugar un nuevo comienzo, pero ahora podemos decir que, aunque esto es cierto, solo lo es parcialmente, debido a que la pregunta por el tiempo, como hemos visto, se encuentra ligada a la pregunta por la propia existencia de cara a la Trinidad Eterna, que empuja al hombre Agustín a pensar su ser temporal.

Después de que se plantea la pregunta por el tiempo, de inmediato, el santo plantea la paradoja de los tres tiempos, pasado, presente y futuro, para establecer cuál es su realidad ontológica:

Lo que sí digo sin vacilación es que sé que si nada pasase no habría tiempo pasado; y si nada sucediese, no habría tiempo futuro; y si nada existiese, no habría tiempo presente. Pero aquellos dos tiempos, pretérito y futuro, ¿cómo pueden ser, si el pretérito ya no es él y el futuro todavía no es? Y en cuanto al presente, si fuese siempre presente y no pasase a ser pretérito, ya no sería tiempo, sino eternidad. Si, pues, el presente, para ser tiempo es necesario que pase a ser pretérito, ¿̇cómo decimos que existe éste, cuya causa o razón de ser está en dejar de ser, de tal modo que no podemos decir con verdad que existe el tiempo sino en cuanto tiende a no ser? (XI, 14, 17)

El terreno que ahora pisamos es árido, ya que puestas así las cosas parece que el ser del tiempo es paradójicamente su no-ser. Es una dificultad doble: por un lado, se parte de lo que se cree saber; por otro lado, se muestra que lo que no se sabe proporciona mayores dificultades. Este saber y no-saber del que investiga parece hacer referencia implícita al ser y no-ser de la naturaleza de lo que se pregunta: el tiempo. La pregunta filosófica por el tiempo nos muestra, al modo socrático, la ignorancia en la cual nos encontramos frente al asunto que investigamos; no obstante, el modo agustiniano de preguntar supera al socrático, pues no se pregunta por una forma estable que debemos parir, sino por una realidad inestable, cambiante, por el fluir mismo. Además, no solo se plantea el asunto de los tres 
momentos del tiempo, sino que se aclara que hablar del tiempo presupone hablar de realidades que cambian, es decir, de cosas atravesadas por el tiempo, que tienen un comienzo y que con el paso del tiempo se deterioran y terminan. El tiempo pasa y ese paso lo notamos en las creaturas. Pero el asunto, como más adelante veremos, no solo radica en este tiempo que se genera y termina, sino que el santo quiere remontarse a un tiempo que no cambie, que permanezca, lo que ya en sí mismo no sería tiempo, sino eternidad, es decir, quiere superar el contexto del fluir cosmológico y ascender a un contexto de naturaleza divina.

Paso seguido, en los dos siguientes numerales, 18 y 19, el santo pasa de la pregunta por el tiempo a la medida del tiempo, ya que cuando mentamos un tiempo breve o un tiempo largo estamos hablando de una medida que hacemos del tiempo, sea una hora, un día, un año o un siglo:

Decimos "tiempo largo" y "tiempo breve", lo cual no podemos decirlo más que del tiempo pasado y futuro. Llamamos tiempo pasado largo, v.gr., a cien años antes de ahora, y de igual modo tiempo futuro largo a cien años después; tiempo pretérito breve, si decimos, por ejemplo, hace diez días, y tiempo futuro breve, si dentro de diez días. Pero ¿cómo puede ser largo o breve lo que no es? Porque el pretérito ya no es, y el futuro todavía no es. No digamos, pues, que "es largo", sino, hablando del pretérito, digamos que "fue largo", y del futuro, que "será largo". (XI, 15, 18)

El problema de la medida del tiempo llega con el objetivo, no de establecer cuál ha de ser la justa medida de esta realidad, sino de mostrar la diferencia que existe entre el tiempo y su medida. La pregunta es: ¿qué es lo que medimos?, ya que nos ha dicho que el pasado ya no es, el futuro no es todavía, y el presente no siempre está presente. ¿Por qué decir que el presente no siempre está presente? ¿Tiene esto sentido? En los tres momentos del tiempo se nos revela la no existencia del tiempo (non-esse), pero ¿cómo negar la existencia de algo que de alguna manera sabemos que es? El presente, aunque tiende al no-ser del pasado, puede ser visto como una imagen de la eternidad que es siempre presente. Si bien, en Dios no existe ni pasado ni futuro Agustín no afirma en realidad la no existencia del pasado y del futuro, en tanto que el primero ya no-es y el segundo aún no-es, sino que "él está diciendo que el pasado, el presente y el futuro no existen como puntos de vista en el que pueden participar en la contemplación de la Palabra de Dios" (Vaught, 2005, p. 126). El asunto, como hemos insistido varias veces, 
radica en comprender la pregunta por el tiempo de cara al deseo interno del santo por comprender mejor las palabras de Génesis, y el tiempo y lugar de descanso que tiene para ello no lo encuentra en ninguno de estos tres momentos; por ello, de manera temprana en el parágrafo 2 , el santo declara cuál es su deseo ardiente de meditar la Ley divina:

Pero ¿cuándo podré yo suficientemente referir con la lengua de mi pluma todas tus exhortaciones, todos tus terrores y consolaciones y direcciones, a través de los cuales me llevaste a predicar tu Palabra y dispensar tu Sacramento a tu pueblo? Mas aunque fuese bastante a referir por orden estas cosas, me cuestan caras las gotas de tiempo y desde antiguo ardo en deseos de meditar tu ley y "confesarte en ella mi ciencia y mi impericia, las primicias de tu iluminación y las reliquias de mis tinieblas", hasta que la flaqueza sea devorada por la fortaleza, y no quiero que se me vayan en otra cosa las horas que me dejen libres las necesidades de la refección del cuerpo, de la atención del alma y de la servidumbre que debemos a los hombres, y la que no debemos, y, sin embargo, les damos.

Nótese que el momento de descanso que busca el santo nos permite establecer nuevamente un vínculo con el comienzo de Confesiones, donde Agustín expone claramente su sed de Dios y su existencial inquietud por comprender las verdades eternas: "Con todo, quiere alabarte el hombre, pequeña parte de tu creación. Tú mismo le excitas a ello, haciendo que se deleite en alabarte, porque nos has hecho para ti y nuestro corazón está inquieto hasta que descanse en ti" $(\mathrm{I}, 1,1)$. El anhelo o intentio de eternidad que es esencial al hombre nos llevará a reconocer que en la fugacidad del tiempo presente encontramos una imagen de la eternidad donde tendrá lugar nuestro descanso. Aunque el ser del tiempo tiende al no-ser, sin embargo, y a pesar de su fugacidad, el tiempo presente es; de ahí que podemos afirmar que el presente tiene una prioridad ontológica frente a los otros dos momentos del tiempo: "Si, pues, hay algo de tiempo que se pueda concebir como indivisible en partes, por pequeñísimas que éstas sean, sólo ese momento es el que debe decirse presente; el cual, sin embargo, vuela tan rápidamente del futuro al pasado, que no se detiene ni un instante siquiera. Porque, si se detuviese, podría dividirse en pretérito y futuro, y el presente no tiene espacio ninguno" (XI, 15, 20). De este modo, el presente se nos revela con mayor claridad que las otras dos dimensiones del tiempo y, por lo tanto, es incierta la 
existencia del pasado y del futuro. La respuesta a este problema la da Agustín en el parágrafo 22 :

Pregunto yo, Padre, no afirmo: ¡oh Dios mío!, presídeme y gobiérname. ¿Quién hay que me diga que no son tres los tiempos, como aprendimos de niños y enseñamos a los niños: pretérito, presente y futuro, sino solamente presente, por no existir aquellos dos? ¿Acaso también existen éstos, pero como procediendo de un sitio oculto cuando de futuro se hace presente o retirándose a un lugar oculto cuando de presente se hace pretérito? Porque si aún no son, ¿dónde los vieron los que predijeron cosas futuras?; porque en modo alguno puede ser visto lo que no es. Y los que narran cosas pasadas no narrarán cosas verdaderas, ciertamente, si no viesen aquéllas con el alma, las cuales, si fuesen nada, no podrían ser vistas de ningún modo. Luego existen las cosas futuras y las pretéritas.

Así, la existencia de las cosas pretéritas y de las futuras no se da sino en el alma, ya que lo pretérito está presente para el alma gracias a la memoria, y el futuro, como premeditación de las acciones futuras, de tal manera que cuando las realizamos ya no son futuras sino presentes:

Así, pues, de cualquier modo que se halle este arcano presentimiento de los futuros, lo cierto es que no se puede ver sino lo que es. Mas lo que es ya, no es futuro, sino presente. Luego cuando se dice que se ven las cosas futuras, no se ven estas mismas, que todavía no son, esto es, las cosas que son futuras, sino a lo más sus causas o signos, que existen ya, y por consiguiente ya no son futuras, sino presentes a los que las ven, y por medio de ellos, concebidos en el alma, son predichos los futuros. Los cuales conceptos existen ya a su vez, y los intuyen presentes en sí quienes predicen aquéllos. (XI, 18, 24)

La existencia de las dimensiones temporales pasado y futuro se puede afirmar gracias a la distinción entre tiempo y medida del tiempo, ya que esta última tiene su fundamento en el alma misma que es la que mide lo que ella hace presente en su interior: "Agustín arguye que la práctica de medir el tiempo está basada en las facultades del alma humana de anticipar el futuro, recordar el pasado, y de ser conscientes del presente a través de la percepción” (Knuuttila, 2002, p. 112). En este sentido, podemos decir que el pasado y el futuro existen en relación con el presente, de ahí que el santo en el parágrafo 26 afirme:

Pero lo que ahora es claro y manifiesto es que no existen los pretéritos ni los futuros, ni se puede decir con propiedad que son tres los tiempos: pretérito, 
presente y futuro; sino que tal vez sería más propio decir que los tiempos son tres: presente de las cosas pasadas, presente de las cosas presentes y presente de las futuras. Porque éstas son tres cosas que existen de algún modo en el alma, y fuera de ella yo no veo que existan: presente de cosas pasadas (memoria), presente de cosas presentes (visión) y presente de cosas futuras (expectación).

Por este motivo, solo en el alma están presentes estas tres realidades, pero no como el sentido común nos lo da a entender, sino como la razón, meditando la Ley divina, puede comprender, de tal suerte que es lícito decir que existe el pasado, el presente y el futuro, aunque esto se diga de modo impropio con tal de que se comprenda en realidad qué es lo que se está diciendo: "Puede decirse también que son tres los tiempos: presente, pasado y futuro, como abusivamente dice la costumbre; dígase así, que yo no curo de ello, ni me opongo, ni lo reprendo; con tal que se entienda lo que se dice y no se tome por ya existente lo que está por venir ni lo que es ya pasado" (XI, 20,26). El tiempo existe en el alma humana porque es en el alma donde se presentan tanto el pasado como el presente y el futuro; en sentido estricto, habría que decir que los tiempos son tres: el presente del pasado, el presente del presente y el presente del futuro. Es en el alma donde se hallan estas tres dimensiones del tiempo, allí es donde hay una suerte de tríada en el alma: el presente del pasado, es decir, la memoria; el presente del presente, la atención, y el presente del futuro, la expectación.

Las paradojas que hemos expuesto alcanzan una dimensión y profundidad en la obra de San Agustín de tal magnitud que difícilmente se encuentre alguien que haya logrado una comprensión mayor que la del Hiponense sobre el asunto del tiempo en relación con alma humana, lo que nos confirma la importancia y la pertinencia que ha tenido y tiene para la filosofía la investigación agustiniana sobre el tiempo ${ }^{6}$. El modo como el santo asume el problema del tiempo se podría calificar como laberíntico, pero después de tratar de comprender en qué consisten estas paradojas esenciales al tiempo nos damos cuenta de que el adjetivo se queda corto para expresar lo difícil del asunto, ya que el tratado sobre el tiempo es interminable. Si nos preguntamos junto con San Agustín ¿qué es pues el

6 Aunque podemos ver un vínculo entre los análisis agustinianos sobre el tiempo y el movimiento con los análisis de Aristóteles en la Física, no se aborda aquí este problema por el mismo propósito de la investigación. Para ver este vínculo: Simo Knuuttila (2002) donde se abordan con detalle las relaciones entre uno y otro análisis. 
tiempo?, nos encontramos con una serie de dificultades cuyas soluciones nos conducen a otras de mayor complejidad, y estas, a su vez, a otras que no solo desbordan nuestra comprensión, sino también nuestras palabras, puesto que el lenguaje mismo se queda corto para explicar este misterio. La existencia humana en el tiempo afecta no solo la experiencia, sino también el lenguaje. "En este sentido la experiencia humana del tiempo es compendiada en la experiencia humana del lenguaje. El lenguaje también enredado en el tiempo y, como la experiencia, el lenguaje debe esperar el paso lineal de ser (presente) al no-ser (pasado) antes de que pueda ser entendido retrospectivamente" (Fredriksen, 2012, p. 95) y su experiencia traída al presente por el alma. Agustín expresa esta complejidad con la cual nos hemos topado tanto al final del parágrafo 27 como a lo largo del 28, que denominamos primer tránsito, donde eleva una súplica casi desgarradora, pidiendo el auxilio de Dios para que su mente sea iluminada y comprenda algo de las profundidades de este misterio. Una vez se ha creído comprender el asunto de la existencia de los tres tiempos, el santo se pregunta:

¿Qué es lo que medimos sino el tiempo en algún espacio? Porque no decimos: sencillo, o doble, o triple, o igual y otras cosas semejantes relativas al tiempo, sino refiriéndonos a espacios de tiempo. ¿En qué espacio de tiempo, pues, medimos el tiempo que pasa? ¿Acaso en el futuro, de donde viene? Pero lo que aún no es no lo podemos medir. ¿ Tal vez en el presente, por donde pasa? Pero tampoco podemos medir el espacio que es nulo. ¿Será, por ventura, en el pasado, adonde camina? Pero lo que ya no es no podemos medirlo. (XI, 21, 27)

La situación en la cual se encuentra el santo, y con él nosotros mismos, es sin lugar a dudas desesperanzadora, pues parece que no hubiésemos avanzado nada en la investigación, de una pregunta pasamos a muchas más, luego ¿qué hemos logrado? ¿Para qué continuar si parece que no tenemos nada en nuestras manos? "La reflexión revela que el presente mismo es un punctum inasible, difícil de alcanzar" (Fredriksen, 2012, p. 95), es una realidad efímera que se encuentra entre dos tipos de no-ser: el pasado, que ya no-es, y el futuro, que todavía no-es. Sin embargo, a pesar de lo enigmático de este enredo, nuestra comprensión del problema del tiempo ha aumentado significativamente, y aunque no sabemos qué es el tiempo, sí entendemos algo de su situación ontológica y de los problemas internos que surgen de tomar como asunto serio la pregunta por el tiempo. 
El enredo al cual ha llegado el Hiponense lo conduce a reconocer tanto el carácter enigmático del tiempo como los arduos trabajos que exige la presente investigación: "Enardecido se ha mi alma en deseos de conocer este enredadísimo enigma. No quieras ocultar, Señor Dios mío, Padre bueno, te lo suplico por Cristo, no quieras ocultar a mi deseo estas cosas tan usuales como escondidas, antes bien penetre en ellas y aparezcan claras, esclarecidas, Señor, por tu misericordia" (XI, 22, 28). Agustín eleva su oración a Dios para que por el Hijo, que es el Verbo Encarnado, le sea revelado cuanto sea posible de esta realidad oculta y, a la vez, tan familiar para el hombre. La súplica del santo nos permite reconocer que las paradojas que hemos expuesto jamás serán resueltas del todo para la mente humana, solo en Dios se da esta claridad, pues, para comprender completamente lo que es el tiempo, es necesario entender su carácter de imagen de la eternidad, lo cual es imposible para el entendimiento humano. En la medida en que no es posible comprender plenamente qué es la eternidad, tampoco se puede entender completamente qué es el tiempo en tanto imagen de la eternidad.

\section{Relación entre tiempo, espacio y movimiento (XI, 23, 29 - XI, 24, 31)}

Al final de la segunda parte del libro Xi, en el parágrafo 27, Agustín muestra la relación directa que tiene la medida del tiempo y el espacio, ya que no medimos el tiempo en términos temporales, sino en términos espaciales: “¿qué es lo que medimos sino el tiempo en algún espacio? Porque no decimos: sencillo, o doble, o triple, o igual y otras cosas semejantes relativas al tiempo, sino refiriéndonos a espacios de tiempo". En este sentido, la conclusión de Agustín es que el pasado, el presente, y el futuro no se pueden medir en cuanto tales, solo se puede medir el tiempo cuando pasa de lo que no existe, por lo que carece de espacio, a lo que ya no existe, que también carece de espacio. Y, sin embargo, ¿̨cómo medir aquello que no tiene espacio determinado? En el análisis agustiniano "la vaguedad de la expresión en cuestión lo conducirá a un concepto de espacio en un sentido amplio del término, y "espacio" se convierte en un fenómeno exclusivamente temporal” (Vaught, 2005, p. 131). La medida del tiempo tanto desde el punto de vista vulgar como desde el punto de vista ontológico se hace en términos espaciales, pues no hay en el lenguaje humano posibilidad de expresar la medida del tiempo en términos temporales, la medida en este sentido es espacial. Un cuerpo 
pasa y la medida de este paso se da en el espacio. En consecuencia, parece inseparable el tiempo del espacio, de ahí que inmediatamente se encuentre un vínculo con el movimiento, ya que todo cuerpo se mueve y el movimiento mismo se da en un determinado tiempo. "Con entusiasmo renovado Agustín intenta, una vez más, dar precisión verbal a la naturaleza del tiempo antes de decir cómo medirlo. Para resolver el problema, podemos identificar el tiempo con el movimiento" (Hausheer, 1937, p. 506). Así, movimiento y fluir del tiempo encuentran en este punto una relación esencial, pero, como veremos, no indistinguible. Agustín ha mostrado que toda creatura tiene un principio y esto nos indica que si efectivamente las creaturas han comenzado a ser, en este mismo acto de empezar a ser debe haber empezado a ser junto con ellas su modo propio de duración: el tiempo. "Es más, su existencia es perfectamente paralela a la existencia de la creatura que dura, a tal punto que el existir del tiempo depende del existir de la creatura, pues no puede haber tiempo sin una creatura que cambie, que sufra alguna mutación o realice algún movimiento" (Benavides, 2007, p. 210), puesto que cuando Dios crea el mundo, crea el tiempo que le es inherente, de tal suerte que el principio de la creatura es el mismo principio del tiempo.

En este punto el santo refuta la posibilidad de que el tiempo sea considerado como el movimiento de los cuerpos celestes, debido a que el tiempo es más fundamental que el movimiento mismo de los astros, aunque ambos estén ligados. Esto porque aunque se detuvieran el sol, la luna y las estrellas y continuara, en cambio, el movimiento de la rueda de un alfarero, ¿cómo afirmar que no hay paso del tiempo en este movimiento? Incluso preguntándose estas cosas, ¿̨no estarían estas palabras en el tiempo? Agustín concluye su argumento diciendo que aun cuando el concepto de día no tuvieran ninguna aplicación por la detención de los astros, no por ello dejaría de existir el tiempo: "Son las estrellas y luminares del cielo 'signos para distinguir los tiempos, días y años'; lo son sin duda; pero ni yo diría que una vuelta de aquella ruedecilla de madera es un día, ni tampoco, por lo mismo, podría decir que dicha vuelta no es tiempo" (XI, 23, 29).

Enseguida, el santo continúa su discusión sobre el tiempo teniendo como base el concepto de un día. Reflexionar sobre este concepto implica "considerar las siguientes posibilidades: "(1) el movimiento del sol de oriente a oriente constituye un día, (2) el período en que este movimiento se produce es un día, y (3) un día es el movimiento y el período en conjunto" (Vaught, 2005, p. 131). En los 
tres casos surgen nuevas paradojas que desvirtúan la investigación agustiniana, ya que se equipara el tiempo con el movimiento de los astros y, por lo tanto, de la pregunta por la naturaleza del tiempo se pasaría a la pregunta por el movimiento celeste, lo que ya es un asunto diferente al que nos preocupa. Por ello, Agustín vuelve a recordar cuál es la dificultad que lo ha conducido a tales paradojas: "Mas no trato ahora de investigar qué es lo que llamamos día, sino qué es el tiempo" (XI, 23, 30). E, inmediatamente, declara al final del parágrafo de qué forma entiende el tiempo, esto es, como una distensión, asunto que analizaremos en la siguiente sección: "Veo, pues, que el tiempo es una cierta distensión. Pero ¿̨lo veo o es que me figuro verlo? Tú me lo mostrarás, ¡oh Luz de la verdad!”. Por ahora el santo solo nombra este asunto, pues antes debe aclarar el vínculo que existe entre el tiempo y el movimiento corpóreo.

En el parágrafo 31 tenemos la clave para poder dar una salida a la dificultad que nace en el modo como medimos el tiempo y su relación con el movimiento. Agustín disocia tiempo y movimiento porque una cosa es el movimiento del cuerpo y otra cosa distinta es aquello con que medimos su duración, de ahí que el santo formule la siguiente pregunta retórica: “¿quién no ve cuál de los dos debe decirse tiempo con más propiedad?” (XI, 24, 31), con lo cual muestra la diferencia evidente entre movimiento y tiempo, ya que el tiempo permanece incluso si el movimiento desaparece. El movimiento presupone el tiempo, no el tiempo el movimiento. El enredo nace, pues, tanto de una comprensión vulgar del tiempo (tiempo astronómico) con respecto al tiempo en cuanto tal (tiempo ontológico) como de una insuficiencia del lenguaje común para distinguir uno del otro. "La medida del tiempo de un movimiento está ligada a la percepción de espacio e implica la captura del lugar donde el movimiento comienza y donde termina. Pero, entonces, no es el tiempo el que se mide por el movimiento, sino al contrario, el movimiento se mide por el tiempo" (Alaux, 1999, p. 2). De ahí que concluya que el tiempo no es el movimiento de los cuerpos, pues es una realidad independiente de este, aunque comparte, de algún modo, la naturaleza inestable esencial a estas dos realidades.

Luego de haber establecido esta distinción entre tiempo y movimiento, Agustín reitera en este segundo tránsito del parágrafo 32 cuán poco parece haber avanzado con respecto a su entendimiento del asunto, pues, aunque ya llevamos treinta y un parágrafos hablando sobre el tiempo, no sabemos aún qué sea este y, 
sin embargo, todo cuanto se ha dicho se ha dicho en el tiempo. No solo la investigación sobre el tiempo nos genera una serie de paradojas sobre lo que comprendemos de él, sino que esta realidad nos acompaña a cada momento, somos temporales y esa misma cercanía con el problema genera, tanto en el santo como en nosotros, una existencial inestabilidad e inseguridad, de ahí que se haga necesaria la búsqueda del auxilio divino, pues nuestra ignorancia parece aumentar a cada paso: "Confiésote, Señor, que ignoro aún qué sea el tiempo; y confiésote asimismo, Señor, saber que digo estas cosas en el tiempo, y que hace mucho que estoy hablando del tiempo, y que este mismo 'hace mucho' no sería lo que es si no fuera por la duración del tiempo" (XI, 25, 32). Se pregunta por el tiempo, en el tiempo y mientras pasa el tiempo. ¿Cómo saber algo de una realidad que escapa y tiende al no-ser? Esta es la desesperada situación en la que nos encontramos junto al Hiponense. Agustín sabe que ignora qué es el tiempo pero, a la vez, reconoce que sabe algo de él y que no logra expresarlo, de tal suerte que no sabe con certeza qué sabe y qué ignora con respecto al tiempo: “¿O es tal vez que ignoro cómo he de decir lo que sé? ¡Ay de mí, que no sé siquiera lo que ignoro!” (XI, 25, 32). En una encrucijada como esta solo una actitud suplicante cabe para el santo, pues el asunto que trata de comprender lo supera en mucho, pues su propia existencia es temporal.

5. Distentio animi (XI, 26, 33 - XI, 28, 38)

LUego de esta Sentida súplica, Agustín continúa con la discusión retomando la afirmación provisional del final del parágrafo 30 donde había declarado que entendía el tiempo como una distentio: "Veo, pues, que el tiempo es una cierta distensión. Pero ¿̇lo veo o es que me figuro verlo? Tú me lo mostrarás, joh Luz de la verdad!". Agustín parece vacilar en el uso del término distentio debido al significado mismo de la palabra. "Distentio significa algo que 'estira' y 'separa, ampliado y extendido, a menudo en direcciones diferentes. El tercer significado de la palabra es una forma ideal de transmitir la riqueza de lo que Agustín quiere comunicar cuando afirma que el presente puede ser medido solo si se extiende en un espacio determinado" (Vaught, 2005, p. 132). Lo que Agustín está anticipando es una extensión análoga a la espacial, pero una medida que se da en el interior del hombre, donde es posible incluir a un mismo tiempo el pasado, el presente y 
el futuro como elementos constitutivos de una misma realidad. A diferencia del estatismo espacial, hay un dinamismo interno en esa medida, que se vincula a la naturaleza misma tanto del tiempo como del que mide el tiempo.

En el parágrafo 33 Agustín comienza preguntando: “¿Acaso no te confiesa mi alma con confesión verídica que yo mido los tiempos? (Nonne tibi confiteor anima mea confessione veridica metiri me tempora?)". Nótese el énfasis que el santo le da al 'yo' de la pregunta, ya que esta pregunta nos recuerda el énfasis del 'yo' del pasaje del libro décimo donde hablando de la memoria afirma: "Y esto es el alma y esto soy yo mismo (et hoc animus est, et hoc ego ipse sum)" (X, 17, 26). Tanto el me del libro XI como el ego ipse del libro X se refieren al que pregunta y confiesa, al hombre Agustín. Ese yo mismo es el alma que pregunta y es ese mismo yo, esa misma alma la que mide los tiempos: "Cierto es, Señor, Dios mío, que yo mido - y no sé lo que mido-, que mido el movimiento del cuerpo por el tiempo; pero ¿no mido también el tiempo mismo? [...] Pero ¿de dónde mido yo el tiempo?" (XI, 26, 33). El de dónde (unde) de la última pregunta es un de dónde que en el contexto del pensamiento agustiniano no nos remite a un lugar, sino a la existencia. La palabra dónde, como lo menciona Agustín en diálogo con su amigo Evodio en De quantitate animae, tiene varios sentidos: "Al preguntar de dónde viene el alma, se me ocurren dos cosas, ya que es distinto decir de dónde viene el hombre, queriendo con eso averiguar su patria, y decir de qué consta, es decir, de qué elementos está compuesto" (Quant. I, 2), esto es, con ella se puede preguntar de dónde viene un hombre, su patria, o de qué está formada una cosa, o cuál es la causa de una cosa o de una actividad. Así, podemos notar que en este contexto Agustín pregunta por la causa. Ese dónde se encuentra, pues, en el ego ipse, esto es, en el alma. Así, podemos entender en qué sentido decíamos al comienzo de nuestra investigación que la pregunta por el tiempo es a la vez la pregunta por sí mismo. Por tal motivo, la investigación por el tiempo es una tarea que comprende toda la existencia.

Una vez formula la pregunta, el Hiponense establece la diferencia que existe entre la medida de los lugares y la medida que hacemos de los tiempos, pues no se puede medir el tiempo como se mide el espacio, ni siquiera se lo puede medir como medimos la duración de las palabras o las sílabas, ya que "puede suceder que un verso más breve suene durante más largo espacio de tiempo, si se pronuncia más lentamente, que otro más largo, si se recita más aprisa. Y lo mismo dígase del poema, del 
pie y de la sílaba" (XI, 26, 33). Sin embargo, el modo como hablamos de la medida de los tiempos nos permite creer que el tiempo es una distensión, pero ¿̇istensión de qué? A lo que Agustín responde que es una distensión del alma. No obstante, el santo concluye el parágrafo diciendo: "Mido el tiempo, lo sé; pero ni mido el futuro, que aún no es; ni mido el presente, que no se extiende por ningún espacio; ni mido el pretérito, que ya no existe. ¿Qué es, pues, lo que mido? ¿Acaso los tiempos que pasan, no los pasados? Así lo tengo dicho ya”. Esa distensión del alma recurre a términos espaciales, ya que "solo podemos medir los tiempos a medida que pasan por un 'espacio' en un sentido amplio del término, y debemos distinguir el espacio como una estructura tridimensional en la que las cosas existen en el 'espacio' en el que los modos temporales se encuentran" (Vaught, 2005, p. 134). Es una extensión en direcciones distintas y todas a un mismo tiempo.

El aprieto que se le presenta al santo consiste en que si, por ejemplo, queremos medir el tiempo de una voz corporal que empieza a sonar, pero mientras no haya sonado, no la podemos medir, pues aún no es, debemos medirla mientras pasa, mas el presente es efímero, no tiene extensión, no dura, en un instante pasa a ser pasado y no podemos medir lo que ya no es, de tal suerte que parece un disparate decir que medimos el tiempo cuando no se nos presenta una realidad que podamos medir. No obstante, es un hecho que medimos el tiempo:

La voz que no ha sido aún terminada no puede ser medida, de modo que se diga "qué larga o breve es", o denominarse igual a otra, ni sencilla o doble, o cosa semejante, respecto de otra. Mas cuando fuere terminada, ya no existirá. ¿Cómo podrá en este caso ser medida? Y, sin embargo, medimos los tiempos, no aquellos que aún no son, ni aquellos que ya no son, ni aquellos que no se extienden con alguna duración, ni aquellos que no tienen términos. No medimos, pues, ni los tiempos futuros, ni los pretéritos, ni los presentes, ni los que corren. Y, sin embargo, medimos los tiempos. (XI, 27, 34)

La situación que se nos presenta es alarmante, pues parece que se pone en duda la realidad misma del tiempo y, al mismo tiempo, hablamos mientras este pasa, es decir, sabemos algo de él, pero no logramos decir a ciencia cierta qué es eso que llamamos tiempo. Para comprender mejor el problema, Agustín recurre al himno ambrosiano Deus creator omnium, que ya había propuesto al comienzo del libro sexto de De Musica. En este punto podemos constatar la continuidad que tiene la investigación sobre el tiempo respecto de sus obras más tempranas, 
no solo por recurrir como ejemplo al himno de San Ambrosio, sino también por el contexto creacional y el vínculo con la memoria que tendrá lugar en este momento de la argumentación. Tanto en Confesiones como en De Musica el verso ambrosiano le permitirá a Agustín comprender la medida del tiempo y cómo la experiencia misma del tiempo tiene lugar en el alma, ya que es el alma la que mide los tiempos.

Agustín utiliza el "silabeo en el canto de un himno - el mismo himno que abrió sus lágrimas, tras la muerte de su madre, Deus creator omnium -, para explicar el paso del tiempo y la función de la memoria" (Conybeare, 2012, p. 108). Con ello, hace referencia a cómo medimos la duración de las sílabas y la proporción de los tiempos que hay entre ellas, pues unas son breves y otras son largas, unas duran un tiempo y las otras el doble de tiempo. ¿Quién mide los tiempos de estas sílabas? :Quién puede decir que una sílaba es doble con respecto a la otra? ¿Dónde se da esta medida? A estas preguntas el santo responde: "Yo las pronuncio y las repito, y veo que es así, en tanto que son percibidas por un sentido fino. En tanto que un sentido fino las acusa, yo mido la sílaba larga por la breve, y noto que la contiene justamente dos veces" (XI, 27, 35). Es el alma, el yo, la que pronuncia y mide.

En este punto es importante hacer evidente el doble movimiento que se presenta en al alma misma del que pregunta por el tiempo. Por un lado, Agustín ha dicho que el tiempo es una distentio animi, y por el otro, hemos visto a lo largo de Confesiones cómo el santo ha confesado ante Dios y los hombres su camino de conversión hacia Dios, es decir, Agustín tiene un anhelo interno hacia su creador que es esa intentio de eternidad esencial al hombre al haber sido creado como imago Dei. El doble movimiento al que nos referimos consiste en que el alma tiende hacia Dios, la intentio, y a la vez se dispersa en la multiplicidad y en la errancia en el tiempo, distentio animi. Ese anhelo de divinidad, esa intentio, propia del alma, se ve contrapuesta a la dispersión ${ }^{7}$ en el tiempo, la distentio animi, que también es propia del alma.

Si nos fijamos en el término distentio, podemos ver con mayor claridad la situación existencial tan compleja a la cual quiere dar respuesta la meditación

$7 \quad$ En este pasaje utilizo el término distentio como dispersión que es una de las posibles traducciones del latín. 
agustiniana. Podemos analizar el término en razón del prefijo inseparable dis. El prefijo “dis" es negativo, "donde 'se estiran y se separan' como una traducción de distentio en una dirección negativa” (Vaught, 2005, p. 132). Puesta así, la distentio fácilmente puede caer en una interpretación equivocada de la palabra, pues, aunque la distentio animi agustiniana en efecto tiene una dimensión negativa ${ }^{8}$, que le viene por su estado de caída, también tiene una dimensión positiva que trataremos de evidenciar con el análisis de los parágrafos 35 a 38. Por lo pronto, es importante decir que para Agustín la distentio encuentra su dimensión positiva, no solo por la posibilidad que el alma tiene de extenderse a la vez en dimensiones distintas y de medir el tiempo valiéndose del espacio, sino porque el alma tiene en sí de manera esencial "la bondad original de la creación y la nueva creación de la conversión" (Vaught, 2005, p. 132), en tanto que es llamada a ser justificada, esto es, a hacerse cada vez más semejante a Dios. De ahí que encontremos que la distentio animi se comprende de cara a la intentio: "La noción de distentio animi sólo necesita para su comprensión del contraste con la intentio inmanente a la 'acción' del espíritu” (Ricœur, 2004, p. 66), aunque este contraste no sea suficiente, ya que no solo se debe ver la distentio de cara a la intentio, sino también de cara a la eternidad misma del Creador, ya que el tiempo es imagen de la eternidad. El movimiento interno del alma es, pues, intentio-distentio 9

Ya habiendo ganado estos elementos, retomemos nuestro análisis de los parágrafos 35 a 38. Hemos dicho que Agustín alude al himno Deus creator omnium de San Ambrosio como medio a través del cual mostrar el modo como el alma puede medir los tiempos. En el parágrafo 35 Agustín ha dicho que es el alma la que pronuncia las sílabas de este verso y las mide: "Yo las pronuncio y las repito

8 En este punto me aparto de la interpretación exclusivamente negativa del término distentio que hace Teske (1996) donde afirma: "Hence, the distention that is time in not merely the being of creatures; it is for us least the penalty of sin from which Christ has come to set us free", sin tener en cuenta la dimensión positiva de la distentio tal como la presento en esta investigación; y del punto de vista de O’Daly, (1977) donde enfatiza: “Augustine does not use distentio and related words in insolation. He uses these words as a part of a group of evocative terms to emphasize the fragmentary, disunited and distracting condition of temporality" (p. 268).

9 Vale la pena mencionar que la distentio animi además es la que nos permite no solo comprender el tiempo personal del alma que se distiende, sino que nos eleva a la comprensión del tiempo de la creación tal como lo abordará Agustín en De Genesi ad litteran y De civitate Dei. A este respecto sostiene Isabelle Bochet en su comentario al libro XI (2009): “El tiempo personal es necesariamente condición para el tiempo como dimensión de la creación” (p. 527). 
[...] yo mido la sílaba larga por la breve", pero esto se da gracias a que en el alma tiene lugar una cierta permanencia de la duración del tiempo y, por ello, puede medir lo que fluye del futuro al pasado, pasando por el efímero presente. "Aquí es notable su énfasis en la forma del verso y la música dentro de la memoria del oyente, y no en lo externo de su realización" (Burton, 2009, p. 147), que apunta a la vivencia misma del tiempo en el alma del que escucha o pronuncia el verso. Es el alma la que se 'estira' (distenditur) de la expectación a la memoria a través de la atención. "En realidad, el estiramiento del alma (distentio animi), extendiendo su actividad en expectación, atención y memoria, es una especie de distracción y dispersión del alma y una consecuencia del pecado original" (Catapano, 2010, p. 573). La estabilidad que busca el santo para poder hablar de una medida del tiempo la encuentra en la distentio animi, gracias a la facultad de la memoria: "Luego no son aquéllas [sílabas], que ya no existen, las que mido, sino mido algo en mi memoria y que permanece en ella fijo" (XI, 27, 35). Este vínculo le permitirá hablar de una duración presente del tiempo que se da en el alma: "En ti, alma mía, mido los tiempos" (XI, 27, 36).

La distentio animi nos permite hablar de esa permanencia del tiempo en el alma que mide, "porque ella espera, atiende y recuerda, a fin de que aquello que espera pase por aquello que atiende a aquello que recuerda" (XI, 28, 37). En este punto es importante mencionar que la estabilidad que el santo busca la encuentra en medio de su referencia al himno ambrosiano, lo que nos permite decir que solo mirando a Dios Creador podemos encontrar esa permanencia que nos concede medir el tiempo, es decir, podemos medir el tiempo por la huella indeleble que tenemos del Eterno en nuestra alma. De este modo, Agustín ha logrado demostrar la existencia de las tres dimensiones del tiempo, pero con sendas referencias al presente que, como ya hemos dicho insistentemente, es el único que podemos medir porque es, por ello Agustín enfatiza:

¿Quién hay, en efecto, que niegue que los futuros aún no son? Y, sin embargo, existe en el alma la expectación de los futuros. ¿Y quién hay que niegue que los pretéritos ya no existen? Y, sin embargo, todavía existe en el alma la memoria de los pretéritos. ¿Y quién hay que niegue que el tiempo presente carece de espacio por pasar en un punto? Y, sin embargo, perdura la atención por donde pase al no ser lo que es. No es, pues, largo el tiempo futuro, que no existe, sino que un futuro largo es una larga expectación del futuro; ni es 
largo el pretérito, que ya no es, sino que un pretérito largo es una larga memoria del pretérito. (XI, 28, 37)

Así, se hace evidente el vínculo que existe entre la distentio animi y la memoria, vínculo que ya se encontraba en el libro VI del De Musica cuando, en el contexto del análisis de las duración de los yambos del himno de San Ambrosio, el santo recurría a la memoria para poder declarar de qué forma podemos distinguir entre la duración de las sílabas, tal como ahora en el libro XI de Confesiones lo ha hecho. No cabe pensar que la mención final del parágrafo 38 a la recitación de un canto se refiera a algo distinto que al Deus creator omnium, ya que dice el santo: "Supongamos que voy a recitar un canto sabido de mí", y iqué otro himno más amado y sabido por el santo que este, tal como él mismo lo declara en el contexto de la muerte de su madre: "Después me quedé dormido; desperté, y hallé en gran parte mitigado mi dolor; y estando solo como estaba en mi lecho, me vinieron a la mente aquellos versos verídicos de tu Ambrosio" (IX, 12, 32). Dicha referencia es la demostración final de Agustín de que efectivamente podemos decir que el tiempo es distentio animi, puesto que en la recitación de este canto sus sílabas se extienden de la expectación, que es futuro, a la memoria, que es pasado, pasando por la atención, que es presente, de tal suerte que se distiende la vida de esta acción en la memoria por lo que se ha dicho y por lo que se ha de decir guardado en ella: "Lo que sucede con el canto entero, acontece con cada una de sus partecillas, y con cada una de sus sílabas; y esto mismo, es lo que sucede con una acción más larga, de la que tal vez es una parte aquel canto” (XI, 28, 38), pues "la atención permanente de la mente proporciona la coincidencia de las tres dimensiones del tiempo" (Hausheer, 1937, p. 508). Y concluye el santo: "Esto lo que acontece con la vida total del hombre, de la que forman parte cada una de las acciones del mismo; y esto lo que ocurre con la vida de la humanidad, de la que son partes las vidas de todos los hombres" (XI, 28, 38). Agustín generaliza su comprensión del tiempo como distentio animi a toda la humanidad en virtud de que esa distensión de las sílabas del canto de la expectación al pasado a través de la atención del presente no solo se da en cada alma en particular, sino que la vida misma de los hombres está atravesada por el tiempo, por ese fluir continuo de la naturaleza misma de la creatura que ha sido creada en el tiempo. La totalidad de la vida de la humanidad se comprende en cada una de sus partes, de tal suerte que si tan solo una insignificante recitación de una sílaba se ve abrazada 
por el fluir del tiempo, de ese paso de la expectación a través de la atención hacia la memoria, de esta misma forma es atravesada toda la vida de un hombre y, por ende, toda la raza humana, que es la suma de las vidas individuales, conformada de innumerables acciones humanas pequeñas, que constituyen acciones cada vez más largas hasta comprender la acción misma de la vida humana, donde efectivamente pasa el tiempo y con él la vida también pasa. Así, encontramos la estabilidad que buscaba Agustín en esa extensión de la memoria, en esa distensión de la vida de la acción en la memoria del ser humano y, como cada hombre es imago $D e i$, se entiende por ello que lo que pasa por creación en un hombre pasa en la totalidad de las creaturas hechas a imagen y semejanza del Creador, esto es, en la vida de la humanidad.

En consecuencia, podemos afirmar que en perspectiva agustiniana, la vida humana misma en tanto que es temporal es intentio-distentio animi. $Y$ eso es posible porque el hombre es imagen y semejanza de Dios y "así como Dios unifica tiempo en el contexto de la eternidad" (Vaught, 2005, p. 139), del mismo modo el alma puede unir memoria (pretérito), atención (presente) y expectación (futuro). Por ello, Agustín al comienzo de sus confesiones mencionaba, refiriéndose a la eternidad divina: "Porque tus años no fenecen, tus años son un constante Hoy [...] Mas tú eres uno mismo, y todas las cosas del mañana y más allá, y todas las cosas de ayer y más atrás, en ese Hoy las haces y en ese Hoy las has hecho" (I, 6, 10). En consecuencia, la relación imagen-modelo se da, no solo entre el alma y su Creador, sino entre el tiempo y la eternidad.

\section{Conclusión del libro (XI, 29, 39 - XI, 31, 41)}

LOS ÚlTIMOS TRES PARÁGRAFOS HACEN LAS VECES DE CONCLUSIÓN del libro XI donde el santo muestra lo poco que logramos comprender del tiempo como imagen de la eternidad, pues queremos comprender algo que en sí mismo es inasible, ya que nuestra propia existencia se encuentra atravesada por aquello que queremos comprender. Por esta razón, la tarea por entender el tiempo es comparable a la tarea por comprendernos a nosotros mismos; a lo sumo, el hombre puede comprender el tiempo como distentio animi. Para Agustín, al final del libro, la vida humana es una distentio animi: "Pero como tu misericordia es mejor que las vidas [de los hombres] (Sal. 62:4), he aquí que mi vida es una distensión. 
Y me recibió tu diestra (Sal. 17:6) en mi Señor, en el Hijo del hombre, mediador entre ti - uno- y nosotros - muchos-, divididos en muchas partes por la multitud de cosas" (XI, 29, 39). Esta distentio se entiende como un movimiento triple debido a la naturaleza múltiple de lo creado que podemos notar en lo que enseguida el santo destaca:

Pero como tu misericordia es mejor que las vidas [de los hombres], he aquí que mi vida es una distensión (distentio). Y me recibió tu diestra en mi Señor, en el Hijo del hombre, mediador entre ti - uno- y nosotros - muchos-, divididos en muchas partes por la multitud de cosas, a fin de que coja por él aquello en lo que yo he sido cogido, y siguiendo al Uno sea recogido de mis días viejos, olvidado de las cosas pasadas, y no distraído (distentus) en las cosas futuras y transitorias, "sino extendido (extentus) en las que están delante de nosotros"; porque no es por la distracción (distentionem), sino por la atención (intentionem), como yo camino hacia la palma de la vocación de lo alto, donde oiré la voz de la alabanza (Sal.25:7) y contemplaré tu delectación (Sal. 26:4), que no viene ni pasa. (XI, 29,39)

Nótese el triple movimiento del que hablamos en las tres acciones propias del alma humana en esta vida temporal: extensión (extensio), atención (intentio) y distracción (distentio). En este parágrafo se traduce distentio como distracción en el mundo que pasa para resaltar la relación que tiene con la naturaleza divina que no viene ni pasa; es decir, se toma distentio en su carácter negativo que, como arriba hemos dicho, le viene por la caída: "él vuelve al concepto negativo de la distensión, según la cual su vida es una distorsión y distracción. De este modo, se aprovecha el 'dis' en distentio, apuntando a las formas en que se separan en direcciones opuestas" (Vaught, 2005, p. 144), esto es, Agustín ahora muestra el carácter negativo que completa el positivo de los análisis de los parágrafos anteriores, especialmente, como ya lo hemos dicho, a partir del 35. Con esto, el Hiponense resalta las dos caras del término distentio que muestra la naturaleza misma de la imago Dei caída, ya que, en tanto que es imagen está llamada a la eternidad y es semejante a su Creador, pero en tanto que se ha pervertido por la soberbia está sujeta a la insuficiencia misma del paso del tiempo. Nótese que el pasaje citado se mueve en la dialéctica tiempo-eternidad y se basa "en las nociones fundamentales de distentio y extensio, con sus respectivas variantes. Entre ellas, se da la mediación, insoslayable, de intentio. Obviamente, los tres vocablos presentan la partícula 
-tent-, que siempre alude a movimiento o tensión, a la que se unen los prefijos dis, in, y ex, para sugerir la dirección de tal movimiento" (Magnavacca, 2002, p. 273). En este punto no queremos determinar el tiempo como algo negativo o imperfecto, sino que el tiempo, aunque es creado de forma perfecta, no es la eternidad que es Dios mismo, de tal suerte que el alma humana por creación anhela ser restituida al estado primigenio en el que fue creada semejante a Dios, por ello, el santo enfatiza al final de parágrafo 39: "Mas ahora mis años se pasan en gemidos (Sal. 30:11). Y tú, consuelo mío, Señor y Padre mío, eres eterno; en tanto que yo me he disipado en los tiempos, cuyo orden ignoro, y mis pensamientos - las entrañas íntimas de mi alma- son despedazadas por las tumultuosas variedades, hasta que, purificado y derretido en el fuego de tu amor, sea fundido en ti”.

Así, vemos que aunque el alma es creada en el tiempo tiene una intentio de eternidad, de ahí que la eternidad y el tiempo sean incompatibles. "El tiempo implica cambio, el movimiento, la transición, la sucesión, la imperfección y la mejora. La eternidad es todo lo que el tiempo no es. Es inmutable, presente en reposo, simultánea al unísono de lo que se desarrolla en el tiempo" (Hausheer, 1937, p. 509). Por ello, anotábamos al comienzo del artículo que el tiempo y la eternidad son inconmensurables. No son de la misma dimensión. En este sentido, la dimensión positiva de la distentio se comprende en relación con la intentio, que arriba llamábamos distentio-intentio animi, y su dimensión negativa se entiende por el estado caído en el cual se encuentra el hombre apartado de Dios donde se refleja "la distorsión y distracción de su situación existencial" (Vaught, 2005, p. 144), de ahí que se distraiga el alma y se disipe en las cosas del mundo, de tal suerte que esta situación no le permite reconocer la estabilidad que se da en su existencia temporal, que hemos hallado gracias a la memoria. Con esto, Agustín recupera la dimensión positiva del alma que tiende a la eternidad y, por ello, debe valerse de la fe que le permite una comprensión de nuestra naturaleza temporal que aspira a la estabilidad propia de la eternidad del Creador. En este sentido podemos entender mejor ese anhelo de tiempo del parágrafo 2 que tanto desea el santo para comprender la Ley divina. De este modo, el tiempo es un 'tiempo' para la meditación, por lo que "Agustín apunta a un concepto de tiempo que se hace posible completamente al hablar del momento en que el alma fluye hacia Dios, purificada y derretida por el fuego del amor" (Vaught, 2005, p. 145), esto es, un alma justificada por el Único mediador entre Dios y los hombres, el 
Hijo, el Verbo divino, un alma que torna a la unidad divina, ya que "por su oposición a la unidad, la distentio fragmenta el alma: al entregarse a distintos objetos de deseo, ella se extravía y acaba por desgarrarse. Cada una de las múltiples vidas humanas, de hecho, se entrega a muchas cosas a través de diversos caminos: y nosotros muchos, divididos en muchas partes por la multitud de cosas (nos multos, in multis per multa) (XI, 29, 39)" (Magnavacca, 2002, p. 273).

En el parágrafo final, el santo eleva una súplica a Dios declarando cuán enigmático es para el hombre el asunto del tiempo, pues solo Aquel que lo creó puede comprenderlo en realidad. Nuestra naturaleza temporal tiene, por tanto, una comprensión limitada del tiempo que se expresa en lo limitado de nuestro lenguaje:

Porque no sucede en ti, inconmutablemente eterno, esto es, creador verdaderamente eterno de las inteligencias, algo de lo que sucede en el que recita u oye recitar un canto conocido, que con la expectación de las palabras futuras y la memoria de las pasadas varía el afecto y se distiende el sentido (affectus sensusque distenditur). Pues así como conociste desde el principio el cielo y la tierra sin variedad de tu conocimiento, así hiciste en el principio el cielo y la tierra sin distinción de tu acción (sine distinctione actionis tuae). (XI, 31, 41)

En este pasaje final de Confesiones, podemos rastrear la genialidad y sutileza del santo en la comparación que hace entre distentio y distinctio, que nos permite identificar, una vez más, la diferencia ontológica fundamental entre la creatura y el Creador. En el ser humano el sentido se da en la distentio, es decir, en el tiempo. Para comprender algo de forma completa debemos esperar que pase de la expectación a la memoria y que el alma se distienda en las dimensiones del tiempo, presente de las cosas futuras, presente del presente y presente de las cosas pretéritas. En Dios, por el contrario, todo es presente, es estable, no hay distinctio en su acción, Él es eterno y su acción es eternamente la misma. Lo que en el hombre es distentio del sentido, esto es, el sentido no se comprende sin el tiempo, vamos entendiendo, en Dios, creador del cielo y la tierra, es una acción sine distinctio. Eso quiere decir que la distinctio es a la creación de las cosas como la distentio es a la comprensión humana. Así, Agustín muestra cómo la distentio es una especie de distinctio reservada para la acción humana. En consecuencia, con la sola acción el hombre no comprende, ya que la comprensión requiere un sentido que sólo se cumple con el paso del tiempo, de esta forma Agustín resalta, una vez más, la dimensión positiva que tiene el tiempo como distentio animi. 
Lejos de Agustín pretender comprender los misterios de lo creado en cuanto tales, ya que su investigación sobre el tiempo no está dada para comprender en realidad qué es el tiempo, sino para, entendiendo algo del tiempo, comprender mejor la Ley divina que es eterna. La comprensión de lo que es el tiempo ha sido velada por la situación de indigencia en la cual se encuentra el alma por su estado caído, así lo que comprendemos del tiempo es de un tiempo caído. De este modo, podemos comprender mejor que las paradojas que surgen cuando preguntamos por el tiempo tienen su fundamento en un tiempo caído, del alma caída. Por ello, la comprensión de lo que es en realidad el tiempo solo se hará plena en la situación de un alma justificada en presencia de Dios; por ahora, cualquier comprensión es una comprensión velada.

\section{Referencias}

\section{OBRA DE SAN AgUSTÍN}

Agustín (1946). Confesiones (Confessiones). Obras completas de San Agustín, Tomo 2. (Trad. Á. Vega, O.S.A.). Madrid: BAC.

Agustín (1964). La Ciudad de Dios (De civitate Dei). Obras completas de San Agustín, Tomo 16. (Trad. P. J. Morán, O.S.A.). Madrid: BAC.

Agustín (1971). La cuantidad del alma (De quantitate animae). Obras completas de San Agustín, Tomo 3, Madrid: BAC.

Agustín (2005). Tratados sobre el Evangelio de San Juan (In Ioannis evangelium tractatus). Obras completas de San Agustín, Tomos 13-14. (Trad. M. Fuertes Lanero \& J. Anoz). Madrid: BAC.

\section{OTRAS FUENTES}

Avramenko, R. (2007). The wound and salve of time: Augustine's politics of human happiness. The Review of Metaphysics, 60 (4), pp. 779-811.

Benavides, V. (2007). Dos visiones del tiempo y la eternidad. Revista Archivum, III(4), pp. 201-216.

Bochet, I. (2009). L'énigme de temps. M. Caron (Dir.), Saint Augustin. Paris: Les Éditions du Cerf. 
Burton, P. (2009). Language in the Confessions of Augustine. New York: Oxford University Press.

Catapano, G. (2010). Augustine. Ll. P. Gerson (Ed.), The Cambridge History of Philosophy in Late Antiquity, Vol. I (pp. 552-581). Cambridge: Cambridge University Press.

Conybeare, C. (2012). Reading the Confessions. M. Vessey (Ed.), A Companion to Augustine (pp. 99-110). Singapore: Wiley-Blackwell.

Cricco, V. (2006). La memoria en San Agustín: imagen del tiempo y enigma de la eternidad. ETIAM. Revista Agustiniana de Pensamiento, I (1), pp. 2-12.

Deferrari, R.J. \& Keeler, M.J. (1929). St. Augustine’s 'City of God': Its Plan and Development. The American Journal of Philology, 50(2), pp. 109-137.

Dodaro, R. (2004). Christ and the Just Society in the Thought of Augustine. New York: Cambridge University Press.

Drobner, H. (2005). Studying Augustine. An overview of recent research. R. Dorado \& G. Lawlees (Eds.), Augustine and his critics. Essays in honour of Gerald Bonner. New York: Routledge, pp. 17-33.

Fitzgerald, A. (Ed.). (2001). Diccionario de San Agustin. San Agustin a través del tiempo (DSA). (Trad. C. Ruiz-Garrido). Burgos: Editorial Monte Carmelo.

Flórez, A. (2008). Mibi quaestio factus sum. La pregunta del hombre por el hombre en Agustín. I. Calderón (Ed.), ¿Quiénes somos? Hacia una comprensión de lo humano (pp. 81-102). Bogotá-Chía: Editorial Universidad de la Sabana.

Fredriksen, P. (2002), The Confessions as Autobiography. E. Stump \& N. Kretzmann (Eds.), Cambridge Companion to Augustine (pp. 87-98). Cambridge: Cambridge University Press.

GunnersdorfJ.W. (1975). Divine Eternity in the Doctrine of St. Augustine. Augustinian Studies, 6, pp. 75-96.

Hausheer, H. (1937). St. Augustine's Conception of Time. The Philosophical Review, 46(5), pp. 503-512.

Hochschild, P. (2012). Memory in Augustine's Theological Anthropology. Oxford: Oxford University Press.

Knuuttila, S. (2002), Time and Creation in Augustine. E. Stump \& N. Kretzmann (Eds.), Cambridge Companion to Augustine (pp. 103-115). Cambridge: Cambridge University Press. 
Lacalle, M. (2006). Tiempo y eternidad en san Agustín. Revista Comunicación y Hombre, 2, pp. 89-99.

Magnavacca, S. (2002). El pasaje de XI, 29, 39 en la estructura de las Confessiones. Teología y Vida, XLIII, pp. 269-284.

O’Daly, G.J.P. (1977). Time as Distentio and St. Augustine's Exegesis of Philippians 3, 12-14. Revue des Études Augustiniennes, XXIII (3-4), pp. 265-271

Pic, A. (2009). Le temps selon Saint Augustin. Lecture du livre XI des Confessions. M. Caron (Dir.), Saint Augustin. Paris: Les Éditions du Cerf, pp. 245-259.

Ricœur, P. (2004). Tiempo y narración. Configuración del tiempo en el relato histórico. México, D.F.: Siglo XXI.

Teske, R.J. (1996). Paradoxes of Time in Saint Augustine. Milwaukee: Marquette University Press.

Vaught, C.G. (2005). Access to God in Augustine's Confessions: Books VII-IX. Albany, USA: State University of New York Press.

Triviño, J. (2014). La investigación agustiniana sobre el tiempo en el De Musica. Revista española de filosofía medieval, 21, pp. 131-152. 